\title{
What Does Google Trends Tell Us about the Impact of Brexit on the Unemployment Rate in the UK?
}

\author{
Mihaela Simionescu ${ }^{1, * \mathbb{C}}$, Dalia Streimikiene ${ }^{2, *}$ (1) and Wadim Strielkowski ${ }^{3}$ \\ 1 Institute for Economic Forecasting of the Romanian Academy, 050711 Bucharest, Romania \\ 2 Lithuanian Institute of Agrarian Economics, 03220 Vilnius, Lithuania \\ 3 Department of Trade and Finance, Faculty of Economics and Management, \\ Czech University of Life Sciences Prague, 165000 Prague, Czech Republic; strielkowski@pef.czu.cz \\ * Correspondence: mihaela_mb1@yahoo.com (M.S.); dalia.streimikiene@lei.lt (D.S.)
}

Received: 14 December 2019; Accepted: 29 January 2020; Published: 31 January 2020

\begin{abstract}
Considering the debate related to the potential effects of Brexit on the UK economy, the aim of this paper is to assess the impact of Brexit on the monthly unemployment rate since the vote for the UK leave from the European Union. This is one of the most important indicators of sustainable development for the country. The novelty of this research is given by the use of microdata to reflect the political instability brought by Brexit, with Google Trends being the tool for collecting the data. Moreover, the data for the four countries that compose the UK are considered (England, Northern Ireland, Scotland, Wales) in a panel data and multilevel framework. The results are consistent with the analysis of important macroeconomic indicators and indicate that Brexit concerns decreased the unemployment rate in the period June 2016-March 2019, with few arguments being provided for this. The state policies should encourage the investment in order to support the future economic growth and sustainable development of the UK.
\end{abstract}

Keywords: Brexit; political instability; sustainable development; unemployment rate; Google Trends; Internet data

\section{Introduction}

The concept of sustainability supposes three dimensions: economic development, social development and environmental protection. The main social dimension of sustainable economic growth is the decrease in unemployment, which is closely linked to investments and the institutional environment, including political stability [1-3]. In this context, the connection between unemployment and political stability, in the sense that a certain political environment ensures a reasonable unemployment in a country, could contribute to the creation of a sustainable economic, social and political framework.

The key role of decent work for all in achieving sustainable development is highlighted by Sustainable Development Goal 8 which aims to "promote sustained, inclusive and sustainable economic growth, full and productive employment and decent work for all". The recent financial and economic crisis has led to soaring unemployment around the world countries, however, before the economic crisis, the job situation was already a major concern in most of the countries as unemployment is the main challenge of sustainable economic growth and social cohesion. The studies argue that unemployment is the threat to the social, economic and political stability of the country as well [1,2].

The possible negative economic and social effects of Brexit need to be analyzed in more details by providing more insights into this as there are many debates around this political decision. There are two groups of economists according to opinion regarding the possible economic effects of Brexit. Most of the economists consider that Brexit will have a negative impact on economic growth, employment, 
foreign investment, trade, and labor migration in the UK. Only few experts anticipate a favorable evolution of the macroeconomic indicators in the post-Brexit period [4]. Labor market in the UK lacked flexibility even in the period before the Brexit announcement and it was one of the causes of Brexit. It is important to empirically assess the first effects of political instabilities related to Brexit on the labor market [5-7].

Considering the debate on Brexit and labor market, the main aim of this paper is to assess the effects of political instability generated by the Brexit announcement on the unemployment rate in the UK [8-10]. The approach is based on two methods: panel data models and multilevel mixed-effects models. The results indicated that the political instability in the UK generated by Brexit determined a lower unemployment rate, with some explanations being provided for this finding.

The novelty of this paper is brought by the use of Google Trends to collect data about Brexit and the use of Internet data for explaining the UK unemployment rate. This approach based on microdata confirms the results using only macroeconomic data analysis.

After this short introduction, the paper makes a presentation of the literature review in the field. The next section comes up with the empirical application and discussion of results. The last part is the conclusion.

\section{Literature Review}

Economists consider that political instability is harmful to the performance of the economy. There are many definitions for political instability, but this paper will focus on the approach of Gyimah-Brempong and Traynor (1999) [11], considering those politically unstable events that change the political behavior and system and also the rules governing business conduct. In most cases, political instability shortens the horizons of policymakers generating suboptimal macroeconomic policies in the short run. The occurrence of these unexpected political and social events could determine frequent changes of economic policies that might increase volatility and reduce macroeconomic performance. There are many channels through which the political environment could influence the performance of the national economy, most of these referring to the determinants of economic growth. Some of these determinants, like government expenditure (structure and level of it), are measurable and can be introduced in econometric models. On the other hand, there are determinants of economic growth like partisanship of the government and expectations of market participants that could not be measured [12]. The influence of the entire political environment in a democratic country, including preferences of the parties and legislature composition, could not be assessed using few measurable policy indicators based on a subjective aggregation of macroeconomic indicators. A solution to this gap in literature is brought by this research where a major political event for the UK like Brexit is expected to affect the economy. Compared to previous studies that focus on macroeconomic indicators from official statistics, the Internet queries for the corresponding keyword Brexit are analyzed and the associated quantitative measures provided by Google Trends are registered.

Prior studies confirmed the hypothesis that an instable political environment negatively affects the economic growth of a country and increases the uncertainty of decision making [13-18]. Economic growth also depends on persistent policies of the government and on the implementation of these policies [19]. The negative impact of political instabilities and social tensions on economic growth will also affect investment since it is not safe to invest in a risky environment. The decrease in the volume of investment reduces the output level generating low employment, high prices, low income. The reduction in domestic productivity will put pressure on imports which could shorten the size of foreign exchange [5]. Contrary to previous studies, Butkiewicz and Yanikkaya (2005) [20] showed a weak influence of social and political instability on economic growth, explaining that the influence is more significant in the case of developed and highly democratic countries.

In modern politico-economic research, coalition governments are considered a threat to the economy [21]. Moreover, there are few recent studies that identified terrorism as a cause of slower economic growth [22-24]. In our study, there is not a high risk of terrorism in the analysed study 
and this keyword was not searched on the Internet in many regions of these countries. Corruption is another issue that has a negative impact on the economic development of some countries [25-29].

Brexit is considered an event with economic, demographic and political drivers [30-33]. It is expected to have lower economic growth, lower foreign direct investment (FDI) and employment in the UK because of Brexit [33-35].

The combination between Brexit and unemployment analysis in the context of big data is a novelty for the literature. None of the studies that explain unemployment based on Internet data using different keywords take into account Brexit or other major political events.

The paper of Askitas and Zimmermann (2009 a) indicated for the first time the significant connection between monthly unemployment in Germany and some Google keyword searches related to this phenomenon [5]. This relationship was utilized in predicting unemployment evolution in the uncertain context of the Great Recession. The used keywords were: unemployment office or agency, most popular search engines in Germany, unemployment rate and Personnel Consultant.

In another seminal work, Askitas and Zimmermann (2009b) proposed updated models based on improved keywords in order to evaluate prediction performance [6]. The authors used the search keywords job search, labor office and short-term work.

The studies in the literature on this topic did not establish if the traditional data sources could completely be replaced by Internet data or if a combination of them is better. Some authors obtained better results when combining the data in their models [36-38]. In our study, we used econometric models to explain the unemployment rate only using official data and Internet data.

The approach of Askitas and Zimmermann (2009a) for modelling the German unemployment rate was applied to other countries [5]. Our study, which models the unemployment rate using Internet data, is the first one for Romania. This type of analysis brings important information for describing unemployment compared to usual time-series models and business cycle indicators.

The most used tool to collect Internet data used in explaining unemployment rate remains Google Trends, this being also used in this study, but the keywords are represented by expressions in the language of the studied country. Moreover, the person that collects the data should indicate the country that represents the area where the searches were made. For US and UK, the keywords were in English, the most frequently used being jobs for the US [39]. Moreover, for the UK, McLaren and Shanbhogue (2011) used the search term data jobs, unemployed, unemployment, unemployment benefit, JSA and Jobseeker's Allowance which were analyzed in connection to the official unemployment rate in the UK using autoregressive models [40]. The model, including the Job Seekers' Allowance model (JSA model), better explained the unemployment compared to the one based only on the official data for unemployment. Google Trends was also used by Dilmaghani (2019) to forecast the unemployment rate in Canada for people between the ages of 25 and 44 years old [41]. The author showed that the intensity of online leisure activities better explains the unemployment and provided better predictions compared to intensity of online jobs. In Latin America, a similar study was developed for Brasil by Lasso and Snijders (2016) which observed a strong correlation between unemployment and variables based on Internet data, with a stronger influence of seasonal patterns [42]. The keywords in Portuguese were: seguro desemprego (unemployment), empregos (jobs) and décimo terceiro salário (13th salary).

A large number of studies focused on southwestern countries using keywords written in the corresponding languages. Most of the research was made for Italy. D'Amuri (2009) and D'Amuri and Marcucci (2009) concluded that the most popular keyword for job searches in Italy is offerte di lavoro (job offers) $[39,43]$. This keyword was employed by Francesco (2009) to prove that the forecasts based on models using Google search data outperformed other types of forecasts for the Italian unemployment rate [44]. Moreover, Naccarato et al. (2015) and Naccarato et al. (2018) also used this keyword [37,38]. Naccarato et al. (2015) connected this keyword to the official unemployment rate from the labor force survey, discovering a cointegration relationship between these variables [37]. This keyword was also used by Naccarato et al. (2018) to predict the youth unemployment rate in Italy using monthly data [38]. The authors used these types of models based on time series: an autoregressive integrated moving 
average model with official data from the labor force survey and a vector-autoregression that combines the previous data with Google Trends data for the keyword offerte di lavoro (job offers). The forecasts based on the combined data outperformed those based only on official data. For Spain, Vicente et al. (2015) collected the data using Google Trends indicators for keywords meaning job offers: oferta de trabajo and oferta de empleo [45]. For France, Fondeur and Karamé (2013) used queries for the word employ, which means jobs, but also employment in French [46]. The authors used a complex method represented by unobserved components models using Kalman filter and the maximum likelihood estimation method. This approach was applied to study unemployment for French young people between the ages of 15 and 24 years.

Moreover, for an entire group of southwestern countries, a comparative analysis was developed, which lead them to conclude that Google Trends data improved the unemployment in France, Italy and Portugal, but not in Spain [47]. The keywords were formulated in the language of each country, focusing not only on unemployment, but also the benefits for the unemployed: in French, chomage, allocations chomage and indemnites de chomage, in Italian, disoccupazione, INPS disoccupazione and disoccupazione ordinaria (INPS is the Italian National Institute for Social Security), in Spanish, desempleo, prestacion desempleo, subsidio de desempleo and in Portuguese, desemprego and subsidio desemprego.

For structures identified with Internet data, the stability could be limited in time even in the case of developed countries $[48,49]$. The challenges are larger for transition and developing countries. Those challenges exist also in traditional data and models.

\section{Methods and Data}

Compared to previous approaches from the economic literature, the novelty of this research is given by the fact that it employs microdata for political instabilities and panel data models for UK countries in certain periods and multilevel mixed-effects models. We used Google Trends to collect data about the searches of the word Brexit in the countries of the UK. The type of cross-section for each country was conditioned by the Internet data. For the UK, we had monthly data for the four countries: England, Northern Ireland, Scotland and Wales.

More panel data models were constructed: fixed-effect/random-effect panel data models. Moreover, multilevel mixed-effects models were built, starting from the fact that the UK has more countries. The dependent variable in all these models were represented by the unemployment rate, International Labour Organization estimate (ILO estimate) (monthly unemployment rate in the UK countries from the Office for National Statistics). The explanatory variables consisted a control variable at the national level (inflation rate) and query indexes for Brexit as the keyword which reflects political instability in the UK. Google Trends provides a time series index that reflects the queries volume of those users introduced into the Google search with the associate keywords in a specific zone (country, region of a country). The query index was calculated as the total query volume in the case of a given keyword that was searched in a specific zone divided by the total number of queries in that area in a certain period. A normalization of 100 is for the maximum query share in that period and a normalization of 0 is for the query share at the initial time $[50,51]$.

The Google Trends tool presents advantages and limits which are described by Askitas and Zimmermann (2009 a) [5]. The "sessionization" indicates that search data are standardized in order to diminish the noise from frivolous repetitions, typing errors, rewrites and other acts. The localization of the search session is made using the IP address of the computer used to initiate sessions. The major advantage consists in the ability to define a group of relevant variables and build the associate content based on the definition and merge of keywords. Therefore, the effects of different concepts could be easily analysed $[48,49]$.

Google Trends is limited to only an aggregate image for the behaviour of microdata. There are not enough details in the methodology and versioning misses. This tool is useful for large search volumes and in those locations with a high Internet penetration rate. The IP address shows only the country. Google might change the commitment related to data provision. The data is extracted from 
a representative subsample which is updated in the case of a new data set. Consequently, the data should be stored to get the precise replications.

Beside the microdata based on Google Trends results, we used the monthly unemployment rate, ILO estimate for the four countries and monthly inflation rate at the national level. These macroeconomic indicators were provided by the Office for National Statistics of the UK and cover the period June 2016-March 2019. Firstly, the presence of unit root was checked in the panel using the Levin-Lin-Chu test, but the panel data for all variables were stationary at the level.

We started the analysis from a regression model based on cross-section and time series data- pooled ordinary least squares-without taking into account fixed or random effects used in the panel approach:

$$
\text { unemployment_rate }_{i t}=\beta_{0}+\sum_{j} \beta_{j} X_{j i t}+e_{i t}
$$

where unemployment_rate $e_{i t}$-unemployment rate for cross-section $i$ at time $t$ (dependent variable), $X_{j i t}$-the $j$-th independent variable for cross-section $i$ at time $t, e_{i t}$-error term, $\beta_{j}$ - $j$-th parameter, $\beta_{0}$-intercept $i=1,2, \ldots, N, t=1,2, \ldots, T$

A transformation of this general model was made to estimate fixed-effects panel data models which allowed us to test for individual effects. Considering a specific spatial effect that is constant in time, the unobserved characteristics could be modeled as fixed effects that appear in the model constant with different values for each cross-section $\left(\beta_{0 i}\right)$. The unobserved heterogenity is controlled considering it is unchanged in time and eventually, correlated with regressors. The one-way fixed effects model for explaining unemployment rate is written as:

$$
\text { unemployment_rate } e_{i t}=\beta_{0 i}+\sum_{j} \beta_{j} X_{j i t}+e_{i t}
$$

where $y_{i t}$-dependent variable for cross-section $i$ at time $t, X_{j i t}$-the $j$-th independent variable for cross-section $i$ at time $t, e_{i t}$-error term, $\beta_{j}$-j-th parameter, $\beta_{0 i}$-unobserved individual effect for cross-section $i$ and constant in time (it captures spatial fixed effects), $i=1,2, \ldots, N, t=1,2, \ldots, T$

If the fixed-effects model includes individual constants, the random-effects model considers the constant as a random variable of mean $\beta_{0}$. Moreover, the spatial differences are random deviations from this constant average:

$$
\beta_{0 i}=\beta_{0}+\varepsilon_{i}
$$

where $\varepsilon_{i}$ represents the error of null average and constant variance $\sigma_{\varepsilon}^{2}$.

The errors present a composite form:

$$
u_{i t}=\varepsilon_{i}+e_{i t}
$$

where $\varepsilon_{i}$-error specific to cross-sections, $e_{i t}$-random error.

The random- effects model for explaining unemployment rate is expressed as:

$$
\text { unemployment_rate }{ }_{i t}=\beta_{0}+\sum_{j} \beta_{j} X_{j i t}+u_{i t}
$$

where $i=1,2, \ldots, N, t=1,2, \ldots, T$.

The Hausman test is employed to select between the fixed-effects and random-effects model.

Time fixed-effects models were also estimated to control for variables that do not change across entities, but change in time. Dummy variables were included for years.

The model (2) could be extended for including the fixed-effects in time (two-way fixed effects model):

$$
\text { unemployment_rate }{ }_{i t}=\beta_{0 i}+\gamma_{i}+\sum_{j} \beta_{j} \cdot X_{j i t}+\varepsilon_{i t},
$$


where $\gamma_{t}$-fixed effects in time.

The impact of time flow on the dependent variable is reflected by changes in macroeconomic policies or phases of the business cycle that affect each cross-section.

Beside panel data models, mixed-effects ML regressions were estimated starting from the observation that each analyzed country is composed by more regions and both fixed effects and random effects are present. We assumed that random effects were present at the cross-section level:

$$
\text { unemployment_rate }=X \beta+Z u+\varepsilon,
$$

where $y$ represents a column vector $(N \times 1)$ for the values of dependent variable, $X$ is a matrix $(N \times p)$ containing $p$ explanatory variables; $\beta$ is a column vector $(p \times 1)$ including fixed-effects regression parameters, $Z$ is the design matrix corresponding to $q$ random effects $(N \times q), u$ is a vector of the random effects $(q \times 1), \varepsilon$ is a column vector $(N \times 1)$ for errors.

\section{Discussion of Results}

According to the random-effects model in Table 1, Brexit had a negative influence on the unemployment rate in the countries of the UK. Our empirical result is consistent with the traditional approaches based on the analysis of macroeconomic indicators [9] and contrary to experts' scenarios in the context of Brexit [52,53]. More searches on Google on the Brexit topic reduced the pressure on the labour market. This result might be explained by the fact that a part of immigrants or citizens left the country and gave up their jobs. The lower unemployment due to reduced migration is also invoked by Coutts et al. (2019) [54]. On the other hand, the fragile political environment determined many of the human resources from informal labour market to employ in legal conditions of work. This might suggest that only a recession that determines a hard Brexit might negatively affect the UK employment.

Table 1. Time random-effects model to explain the unemployment rate in the countries of the UK (2016 July-2019 March).

\begin{tabular}{|c|c|c|c|}
\hline Variable & Coefficient & t-Statistic & $p$-Value \\
\hline Constant & 7.049 & 12.034 & 0.0000 \\
\hline Brexit & -0.029 & -4.166 & 0.0001 \\
\hline Inflation rate & -0.157 & -4.364 & 0.0000 \\
\hline Constant_England & 0.532 & & \\
\hline Constant_Northern Ireland & 0.037 & & \\
\hline Constant_Wales & -0.023 & & \\
\hline Constant_Scotland & -0.546 & & \\
\hline Random Effects (Period) & Coefficient & Random Effects (Period) & Coefficient \\
\hline 2016M06-C & -0.053102 & 2017M11-C & 0.235143 \\
\hline 2016M07-C & -0.031557 & 2017M12-C & 0.005645 \\
\hline 2016M08-C & 0.050321 & 2018M01-C & -0.028340 \\
\hline 2016M09-C & 0.139465 & 2018M02-C & 0.031425 \\
\hline 2016M10-C & 0.176392 & 2018M03-C & -0.080557 \\
\hline 2016M11-C & 0.109060 & 2018M04-C & -0.071887 \\
\hline 2016M12-C & 0.161349 & 2018M05-C & -0.188714 \\
\hline 2017M01-C & 0.060465 & 2018M06-C & -0.052237 \\
\hline 2017M02-C & 0.125258 & 2018M07-C & -0.021123 \\
\hline 2017M03-C & 0.135143 & 2018M08-C & 0.024028 \\
\hline 2017M04-C & 0.032165 & 2018M09-C & 0.004450 \\
\hline 2017M05-C & 0.102695 & 2018M10-C & -0.225246 \\
\hline 2017M06-C & 0.000533 & 2018M11-C & -0.200824 \\
\hline 2017M07-C & 0.016672 & 2018M12-C & -0.127926 \\
\hline 2017M08-C & 0.063419 & 2019M01-C & -0.203551 \\
\hline 2017M09-C & 0.129482 & 2019M02-C & -0.249654 \\
\hline 2017M10-C & 0.142937 & 2019M03-C & -0.211330 \\
\hline
\end{tabular}


These empirical results are confirmed by statistical data. Other economists explained this tendency in unemployment by the fact that companies decided to hire plans till they had a clear image about the political situation in the UK. The firms hired workers to face the growing demand rather than to invest in technology or productivity. The Bank of England showed that companies' investment fell and they do not intend to invest in the near future, but only to meet the demand by the aid of new employees. A significant growth in the number of jobs occupied by old Britons was observed because of the changes in the state pension age.

Random-effects in time were observed during the analysed period. In the first two months, from inertia, the unemployment decreased. Then, there was a tendency of growth for unemployment, followed by a tendency of decrease starting in 2018. The high uncertainty related to the Brexit situation one year and half after the Brexit referendum made the companies adapt and change their attitude related to employment, and new jobs were offered.

Inflation had a negative influence on unemployment, a relationship that is confirmed by economic theory [55]. The unemployment reduced with the cost of higher inflation.

The pooled ordinary least squares (OLS) model in Table 2 confirmed the negative influence of Brexit on the unemployment rate for each country. In Scotland, the effect of the political instability brought by Brexit on unemployment was stronger compared to the rest of the countries.

Table 2. Pooled ordinary least squares (OLS) model to explain unemployment rate in the countries of the UK (2016 July-2019 March).

\begin{tabular}{lccc}
\hline \multicolumn{1}{c}{ Variable } & Coefficient & t-Statistic & $p$-Value \\
\hline Constant & 6.984032 & 13.560 & 0.0000 \\
Inflation rate & -0.159052 & -5.345 & 0.0000 \\
Brexit_England & -0.023485 & -4.441 & 0.0000 \\
Brexit_Northern Ireland & -0.028597 & -4.641 & 0.0000 \\
Brexit_Wales & -0.028606 & -4.304 & 0.0000 \\
Brexit_Scotland & -0.036183 & -4.880 & 0.0000 \\
\hline
\end{tabular}

Source: own computations.

Starting from the fact that UK includes more countries, a multilevel mixed-effects maximum likelihood (ML) model was built and presented in Table 3. It confirmed the negative impact of Brexit on unemployment rate when random effects are considered inside the countries.

Table 3. Multilevel mixed-effects maximum likelihood (ML) model to explain the unemployment rate in the countries of the UK (2016 July-2019 March).

\begin{tabular}{cccc}
\hline Variable & Coefficient & t-Statistic & $p$-Value \\
\hline Brexit & -0.034 & -5.09 & 0.000 \\
Constant & 7.160 & 11.87 & 0.000 \\
Var(constant) & 0.178 & & \\
Var(residual) & 0.281 & & \\
\hline
\end{tabular}

Source: own calculations.

All these econometric models confirmed the companies' behaviour, which prefer to employ people rather than invest till the Brexit situation would be solved in a way. Compared to previous studies based on analysis of macroeconomic indicators, our study comes with a new approach based on microdata that confirms the results at the macroeconomic level. Moreover, our approach based on collecting microdata using Google Trends has also the advantage of nowcasting unemployment rate in a short time compared to the official estimates provided by the statistical office. 
The results of this study show that the long-term impact of Brexit can be very negative in terms of economic growth and employment situation in the UK as the reduced investments due to uncertainty with regards to Brexit would provide long-term negative implications for sustainable development of the UK in the future. Therefore, additional policies are necessary to promote investments and ensure long-term employment opportunities for UK citizens in order to implement Sustainable Development Goal 8, targeting promotion of sustained, inclusive and sustainable economic growth, full and productive employment and decent work for all citizens.

\section{Conclusions}

The use of Google Trends for collecting the data referring to political events was used to assess their impact on macroeconomic variables is a novelty for the economic literature and this new approach will be useful for researchers in their future analyses, but also for political decision-makers in developing future economic policies, for businessmen that plan their economic activities, for citizens in general that might take into consideration the possibility to migrate.

Our empirical results based on microdata are consistent with the analysis based only on macroeconomic data. The results of this paper are useful in terms of providing the assessment of the impact of Brexit for the main social indicator of sustainable development in the UK. Results show that the companies continue to offer new jobs to manage the growing demand in the UK, but there is an obvious aversion to investment because of the uncertain political environment. It is easier to fire employees in the case business contraction would be required than to recover the investment. The macroeconomic policies in the UK should focus on encouraging investment since short-run economic growth ensured by higher employment is not sustainable.

Moreover, some immigrants have left the UK, which gave the opportunity for unemployed natives and other immigrants to get a job, which reduced the unemployment rate. The results are in line with the expectations given by the macroeconomic and microeconomic evolutions after the Brexit vote. For 2020, the experts expect to see a rise in unemployment, because of lower economic growth. In this context, policies that support employment, especially for youth, are necessary. Gaps in regional employment have widened in recent years, with rates that are higher than 10 percentage points in the southwest compared to the northeast of England. Other policies should focus on the reduction of these regional gaps.

The proposed econometric models for explaining the unemployment rate in the UK, based on Internet searches for Brexit, are useful in nowcasting unemployment and detecting the moment when unemployment begins to increase. Our approach is limited by the fact that it depends on the Internet penetration rate which is very high for the UK, but it does not reflect all the people concerns related to Brexit. In future research, a comparison between a traditional analysis based only on macroeconomic data to explain unemployment and our approach will be made.

Author Contributions: All authors equally contributed to the preparation of paper. All authors have read and agreed to the published version of the manuscript.

Funding: This research received no external funding.

Acknowledgments: This paper is part of the study "The simulation of economic processes in R", part of the research program of the Institute for Economic Forecasting of the Romanian Academy for 2020. The paper is dedicated to the 50th anniversary of the establishment of Institute for Economic Forecasting of the Romanian Academy.

Conflicts of Interest: The authors declare no conflict of interest.

\section{References}

1. Colino, A. Conflict Resolution Processes, Uncertainty and Labor Demand. J. Peace Res. 2012, 49, 661-667. [CrossRef]

2. Mursa, G.C.; Iacobuta, A.-O.; Socoliuc, O.-R.; Clipa, R.-I.; Butiseaca, A. Youth Unemployment Among EU Countries-A Challenge for Sustainable Growth and Social Cohesion Shocks. Transform. Bus. Econ. 2018, 17, 701-720. 
3. Roman, A.; Rusu, V.D.; Stoica, O. Institutional Environment and Economic Development in EU Countries: The Impact on New Business Formation Shocks. Transform. Bus. Econ. 2018, 17, 579-603.

4. Simionescu, M.; Zimmermann, K. Big Data and Unemployment Analysis. J. Renmin Univ. China 2017, 31, 2-11.

5. Askitas, N.; Zimmermann, K.F. Google econometrics and unemployment forecasting. Appl. Econ. Q. 2009, 55, 107-120. [CrossRef]

6. Askitas, N.; Zimmermann, K.F. Googlemetrie und Arbeitsmarkt. Wirtschaftsdienst 2009, 89, 489-496. [CrossRef]

7. Barreira, N.; Godinho, P.; Melo, P. Nowcasting unemployment rate and new car sales in south-western Europe with Google Trends. NETNOMICS Econ. Res. Electron. Netw. 2013, 14, 129-165. [CrossRef]

8. Becker, S.O.; Fetzer, T.; Novy, D. Who voted for Brexit? A comprehensive district-level analysis. Econ. Policy 2017, 32, 601-650. [CrossRef]

9. Campos, N.F. B for Brexit: A Survey of the Economics Academic Literature; Institute of Labor Economics: Bonn, Germany, 2019.

10. Coutts, K.; Gudgin, G.; Buchanan, J. How the economics profession got it wrong on Brexit. In European Union; Palgrave Macmillan: Cham, Switzerland, 2019; pp. 251-278.

11. Gyimah-Brempong, K.; Traynor, T.L. Political instability, investment and economic growth in Sub-Saharan Africa. J. Afr. Econ. 1999, 8, 52-86. [CrossRef]

12. Snowberg, E.; Wolfers, J.; Zitzewitz, E. Partisan impacts on the economy: Evidence from prediction markets and close elections. Q. J. Econ. 2007, 122, 807-829. [CrossRef]

13. Aisen, A.; Veiga, F.J. How does political instability affect economic growth? Eur. J. Political Econ. 2013, 29, 151-167. [CrossRef]

14. Barro, R.J. Economic growth in a cross section of countries. Q. J. Econ. 1991, 106, 407-443. [CrossRef]

15. Campos, N.F.; Nugent, J.B. Who is afraid of political instability? J. Dev. Econ. 2002, 67, 157-172. [CrossRef]

16. Görmüş, Ş; Kabasakal, A. Are Economic Crises and Government Changes Related? A Descriptive Statistic Analysis. Int. J. Hum. Soc. Sci. 2010, 5, 13-19.

17. Gupta, D.K. Political psychology and neoclassical theory of economic growth: The possibilities and implications of an attempted resynthesis. Political Psychol. 1987, 8, 637-665. [CrossRef]

18. Jong-A-Pin, R. On the measurement of political instability and its impact on economic growth. Eur. J. Political Econ. 2009, 25, 15-29. [CrossRef]

19. Barro, R.J. Health and economic growth. Ann. Econ. Financ. 2013, 14, 329-366.

20. Butkiewicz, J.L.; Yanikkaya, H. The impact of sociopolitical instability on economic growth: Analysis and implications. J. Policy Modeling 2005, 27, 629-645. [CrossRef]

21. Siermann, C.L. Politics, Institutions and the Economic Performance of Nations; Edward Elgar Publishing: Cheltenham, UK, 1998.

22. Ranga, M.; Pradhan, P. Terrorism terrorizes tourism: Indian tourism effacing myths? Int. J. Saf. Secur. Tour. 2014, 1, 26-39.

23. Tabassam, A.H.; Hashmi, S.H.; Rehman, F.U. Nexus between political instability and economic growth in Pakistan. Procedia Soc. Behav. Sci. 2016, 230, 325-334. [CrossRef]

24. Okafor, G. The impact of political instability on the economic growth of ECOWAS member countries. Def. Peace Econ. 2017, 28, 208-229. [CrossRef]

25. Gyimah-Brempong, K. Corruption, economic growth, and income inequality in Africa. Econ. Gov. 2002, 3, 183-209. [CrossRef]

26. Anoruo, E.; Braha, H. Corruption and economic growth: The African experience. J. Sustain. Dev. Afr. 2005, 7, $43-55$.

27. Serra, D. Empirical determinants of corruption: A sensitivity analysis. Public Choice 2006, 126, $225-256$. [CrossRef]

28. Ugur, M.; Dasgupta, N. Evidence on the Economic Growth Impacts of Corruption in Low-Income Countries and Beyond: A Systematic Review; EPPI-Centre Social Science Research Unit, Institute of Education, University of London: London, UK, 2011.

29. Simionescu, M. European economic integration and migration in Romania. Econ. Res.-Ekon. Istraž. 2019, 32, 3607-3626. [CrossRef]

30. Matthijs, M. Europe after Brexit: A less perfect union. Foreign Aff. 2017, 96, 85.

31. Colantone, I.; Stanig, P. Global competition and Brexit. Am. Political Sci. Rev. 2018, 112, 201-218. [CrossRef] 
32. Culkin, N.; Simmons, R. Shock therapy and entrepreneurial flare\# Brexit. Int. J. Entrep. Behav. Res. 2019, 25, 338-352.

33. Simionescu, M.; Bilan, Y.; Smrčka, L.; Vincúrová, Z. The effects of European economic integration and the impact of brexit on the UK immigrants from the CEE countries. E+ M Ekon. Manag. 2017, 20, 29-47. [CrossRef]

34. Simionescu, M.; Strielkowski, W.; Kalyugina, S. The impact of Brexit on labour migration and labour markets in the United Kingdom and the EU. Terra Econ. 2017, 15, 148-156.

35. Gudgin, G.; Coutts, K.; Gibson, N.; Buchanan, J. The macro-economic impact of Brexit: Using the CBR macro-economic model of the UK economy (UKMOD). J. Self-Gov. Manag. Econ. 2018, 6, 7-49.

36. Chadwick, M.G.; Sengül, G. Nowcasting the Unemployment Rate in Turkey: Let's Ask Google. Cent. Bank Rev. 2015, 15, 15.

37. Naccarato, A.; Falorsi, S.; Loriga, S.; Pierini, A. Combining official and Google Trends data to forecast the Italian youth unemployment rate. Technol. Forecast. Soc. Chang. 2018, 130, 114-122. [CrossRef]

38. Naccarato, A.; Pierini, A.; Falorsi, S. Using Google Trend Data To Predict The Italian Unemployment Rate; (No. 0203); Department of Economics-University Roma Tre: Roma, Italy, 2015.

39. D'Amuri, F.; Marcucci, J. The predictive power of Google searches in forecasting US unemployment. Int. J. Forecast. 2017, 33, 801-816. [CrossRef]

40. McLaren, N.; Shanbhogue, R. Using Internet Search Data as Economic Indicators; Bank of England: London, UK, 2011.

41. Dilmaghani, M. Workopolis or The Pirate Bay: What Does Google Trends Say about the Unemployment Rate? J. Econ. Stud. 2019, 46. (just-accepted). [CrossRef]

42. Lasso, F.; Snijders, S. The power of Google search data; an alternative approach to the measurement of unemployment in Brazil. Stud. Undergrad. Res. E J. 2016, 2, 1-4.

43. Vázquez, R.M.C. Grandes datos, Google y desempleo/Big Data, Google and Unemployment. Estudios Econ. 2020, 35, 125-151.

44. D'Amuri, F. Predicting unemployment in short samples with internet job search query data. MPRA Paper 2009, 18403, 1-18.

45. Vicente, M.R.; López-Menéndez, A.J.; Pérez, R. Forecasting unemployment with internet search data: Does it help to improve predictions when job destruction is skyrocketing? Technol. Forecast. Soc. Chang. 2015, 92, 132-139. [CrossRef]

46. Fondeur, Y.; Karamé, F. Can Google data help predict French youth unemployment? Econ. Model. 2013, 30, 117-125. [CrossRef]

47. Billari, F.; D'Amuri, F.; Marcucci, J. Forecasting births using Google. In Proceedings of the PAA Annual Meeting, New Orleans, LA, USA, 6 April 2013; Available online: https://paa2013.princeton.edu/papers/131393 (accessed on 30 January 2020).

48. Simionescu, M.; Ciuiu, D.; Bilan, Y.; Strielkowski, W. GDP and net migration in some eastern and south-eastern countries of Europe. A panel data and Bayesian approach. Monten. J. Econ. 2016, 12, 161-175. [CrossRef]

49. Simionescu, M. Effects of European economic integration on foreign direct investment: The case of Romania. Econ. Sociol. 2018, 11, 96-105. [CrossRef]

50. Choi, H.; Varian, H. Predicting initial claims for unemployment benefits. Google Inc. 2009, 1, 1-5.

51. Choi, H.; Varian, H. Predicting the present with Google Trends. Econ. Rec. 2012, 88, 2-9. [CrossRef]

52. Bootle, R.; Jessop, J.; Lyons, G.; Minford, P. Alternative Brexit Economic Analysis; Economists for Free Trade: London, UK, 2018; Available online: https:/www.economistsforfreetrade.com/wp-content/uploads/2018/03/ Alternative-Brexit-Economic-Analysis-Final-2-Mar-18.pdf (accessed on 30 January 2020).

53. Lea, R. Brexit: Agreement on the Transition Period; Arbuthnot Banking Group: London, UK, 2018; p. 26.

54. Carrière-Swallow, Y.; Labbé, F. Nowcasting with Google Trends in an emerging market. J. Forecast. 2013, 32, 289-298. [CrossRef]

55. Furtula, S.; Durkalić, D.; Simionescu, M. Testing Phillips Curve for Serbian and Romanian Economy. Rom. Stat. Rev. 2018, 3, 40-56.

(C) 2020 by the authors. Licensee MDPI, Basel, Switzerland. This article is an open access article distributed under the terms and conditions of the Creative Commons Attribution (CC BY) license (http://creativecommons.org/licenses/by/4.0/). 